\title{
Vitamin D Receptor FokI Gene Polymorphism Predicted Poor Response to Treatment in Chronic HCV Genotype 4
}

\author{
Hany Shehab ${ }^{1}$, Dina Sabry ${ }^{*}$, Mai Mukhtar ${ }^{2}$, Wafaa Elakel ${ }^{1}$, Mahasen Mabrouk ${ }^{1}$, \\ Amr Zahra ${ }^{3}$, Gamal Esmat ${ }^{1}$, Amany Y El Kazaz ${ }^{4}$, Amr Zahra ${ }^{3}$ \\ ${ }^{1}$ Cairo University, Cairo, Egypt; ${ }^{2}$ El Talaba hospital, Alexandria, Egypt \\ ${ }^{3}$ Fayoum University. Al Fayoum, Egypt; ${ }^{4}$ Suez Canal University. Ismailia, Egypt.
}

\begin{abstract}
The aim of this study was to investigate the association between a genetic polymorphism of the vitamin D receptor (VDR) and antiviral responses in Egyptian patients with chronic hepatitis $\mathrm{C}$ virus genotype 4 (HCV-4).

Methods: Our study enrolled $100 \mathrm{HCV}-4$ patients who received pegylated interferon alpha-2a (pegIFN $\alpha-2 a)$ and ribavirin for 48 weeks. Patients were divided into 2 groups according to their response to therapy: 50 were responders, and 50 were nonresponders. All HCV-4 patients were further subjected to the following laboratory tests: HCV-RNA using quantitative PCR, vitamin D level using ELISA and VDR genotype using PCR-RFLP assays, and abdominal ultrasonography.

Results: There was a statistically significant difference in the frequency of the VDR polymorphism (FokI rs10735810) between responders (FF:60\%, Ff:16\%, ff:24\%) and non-responders (FF:10\%, Ff:26\%, ff:64\%) $(P<0.001)$. There was a statistically

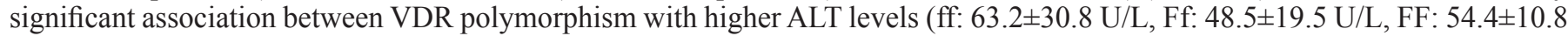
$\mathrm{U} / \mathrm{L}, P=0.04$ ) and higher alkaline phosphatase levels (ff: $102.6 \pm 53.2 \mathrm{U} / \mathrm{L}, \mathrm{Ff}: 100.3 \pm 66.4 \mathrm{U} / \mathrm{L}, \mathrm{FF}: 68.3 \pm 29.4 \mathrm{U} / \mathrm{L}, P=0.007)$. VDR polymorphism showed no association with baseline vitamin D levels $(P=0.21)$.

Conclusion: VDR polymorphism plays a role in the treatment response of $\mathrm{HCV}$ and the modification of disease progression in Egyptians infected with chronic HCV-4. (Int J Biomed. 2016; 6(4):265-270.)
\end{abstract}

Key Words: HCV genotype 4 • response to treatment • vitamin D • FokI polymorphism (rs10735810)

\section{Introduction}

Chronic HCV remains a worldwide health problem with prevalence rates reaching alarming levels in some areas such as Egypt, where the prevalence is $15 \%-22 \% \cdot[1,2]$ For genotype 4, which is the most prevalent form in Egypt, pegIFNa-2a and ribavirin remain the suboptimal "gold standard" for treatment with sustained virologic response rates (SVR) of about $40 \%$ $60 \%{ }^{[2]}$ Despite the emergence of novel direct-acting antivirals, to date no interferon-free regimen has proved as effective as interferon-incorporating regimens and none has yet been approved for the treatment of $\mathrm{HCV}^{[3,5]}$

In the quest to enhance treatment response there has been a relentless search for predictors of response, especially modifiable factors. Recently, the spotlight has been focussed on the role of vitamin $\mathrm{D}$ and its relation to progression and

*Corresponding author: Dina Sabry Abd El Fatah, Professor of Medical Biochemistry and molecular Biology of the Cairo University, Egypt.E-mail: dinasabry@kasralainy.edu.eg response to therapy of $\mathrm{HCV} \cdot{ }^{[6]} \mathrm{A}$ few studies have recently reported the association of serum vitamin D levels with fibrosis levels and response to treatment in genotypes $1,2,3 \mathrm{HCV} \cdot{ }^{[7-9]}$ Some other studies, however, have negated such evidence. ${ }^{[10]}$ Two small trials have reported an improved SVR with vitamin D supplementation. ${ }^{[11,12]}$ Vitamin D is known to have many immunemodulatory roles and possibly roles in modulating the process of fibrogenesis. ${ }^{[13,14]}$ Immune-regulatory actions of vitamin D are thought to be exerted through the nuclear VDR, expressed in antigen-presenting cells and activated $T$ cells. ${ }^{[13-15]}$ VDR determines interference and/or direct interaction with vitamin D responsive elements in the promoter regions of cytokine genes. Analogous to IL28 gene polymorphisms, it was proposed that genetic polymorphisms affecting the vitamin D pathway may significantly affect response to therapy. Only a few studies have addressed a limited number of genetic polymorphisms where the vitamin D 1a-hydroxylase (CYP27B1-1260) promoter polymorphism and VDR polymorphisms (rs1544410, rs7975232 and rs731236) have shown significant association with response in 
genotypes 1,2 and 3. ${ }^{[8,16,17]}$ The VDR FokI gene polymorphism has been implicated in many immunologic processes including breast and prostate cancer, autoimmune hepatitis, primary biliary cirrhosis, and $\mathrm{TB} ;{ }^{[6,18-20]}$ its role in $\mathrm{HCV}$ is yet to be explored.

Our study aimed to assess the relation between VDR genetic polymorphism (FokI rs10735810) and response to therapy in HCV-4 patients. In addition, we also assessed the inter-relation between vitamin $\mathrm{D}$ levels and treatment response.

\section{Materials and Methods}

\section{Patients}

This is a retrospective study assessing the stored sera and whole blood samples of HCV-4 patients who received pegIFN $\alpha-2 a$ and ribavirin. Fifty consecutive responders (RS) and 50 consecutive non-responders (NR) were selected for the study. Inclusion criteria included: treatment-naïve patients who received pegIFN $\alpha-2 a$ (180 ug weekly) and weight-based ribavirin (1000-1200 mg daily) for 48 weeks according to current guidelines, compliance with treatment as defined by receiving $\geq 80 \%$ of drugs especially during the first 12 weeks of treatment, written consent of genetic testing and the presence of pre-stored serum and whole blood samples collected during the month before therapy and at the end of therapy. Patients without the previous criteria or with any of the following criteria were excluded: vitamin D or calcium supplementation during therapy or during the 6 months previous to therapy, bone and rheumatologic disorders and renal disorders of any severity. All patients had liver biopsies taken prior to initiation of treatment, and fibrosis was graded according to the METAVIR model. Clinical and demographic characteristics including age, sex, liver biopsy data, HCV viral load, hematologic indices and clinical biochemistry data were extracted from clinical databases.

\section{Analysis of blood samples}

A $5 \mathrm{ml}$ whole blood sample was divided into 2 parts. The first part was subjected to DNA extraction and followed by assessment of VDR polymorphism rs10735810 (VDRP) by PCR-RFLP analysis. The second part was centrifuged at $3000 \mathrm{xg}$ to separate plasma for further assessment of vitamin D level $(\mathrm{ng} / \mathrm{mL})$ and quantitative HCV-RNA. Other laboratory measurements were assessed: CBC, INR, blood glucose, ALT, AST, albumin, bilirubin, alkaline phosphatase, $\alpha$ feto-protein, and creatinine.

\section{PCR-RFLP analysis}

Total DNA was isolated from mononuclear cells (MNC) using the extraction kit(Qiagene, USA) according to instructions of manufacturer. VDRP rs12979860 genotyping was assessed by RFLP-PCR method, EzWayTM Direct Taq PCR Master mix (Koma Biotech Inc., Seoul, Korea) in $25 \mu \mathrm{L}$ reaction volume. The primers used for PCR-RFLP were Forward 5'AGCTGGCCCTGGCACTGACTCTGCTCT- 3 'and Reverse 5 - ATGGAAACACCTTGCTTCTTCTCCCTC-3' (gene bank accession number: NG008731.1). The thermal cycling profile involved denaturation at $94^{\circ} \mathrm{C}$ for $15 \mathrm{sec}$, annealing at $55^{\circ} \mathrm{C}$ for $30 \mathrm{sec}$, and extension at $72^{\circ} \mathrm{C}$ for $30 \mathrm{sec}$ for 35 cycles.
Final extension was continued at $72^{\circ} \mathrm{C}$ for $10 \mathrm{~min}$. The PCR products were separated by $2 \%$ agarose gel electrophoresis. $10 \mathrm{uL}$ of the PCR products were digested with 1 unit of the FokI restriction endonuclease (New England Biolabs, Hitchin, $\mathrm{UK}$ ) in a total volume of $20 \mathrm{uL}$ at $37^{\circ} \mathrm{C}$ overnight. Both homozygous ( $\mathrm{FF}$ and $\mathrm{ff}$ ) and heterozygous genotypes (Ff) were estimated on $4 \%$ agarose gel.

\section{Vitamin D serum level assessment}

Vitamin D serum level was detected by ELISA 25$\mathrm{OH}$ Vitamin D kit according to instructions of manufactures (DRG, international Inc., USA). The data are expressed as ng/ $\mathrm{mL}$. Grading of vitamin D levels was done as follows: normal $(\geq 30 \mathrm{ng} / \mathrm{mL})$, insufficiency $(>10-<30 \mathrm{ng} / \mathrm{mL})$, and deficiency $(\leq 10 \mathrm{ng} / \mathrm{mL})$.

\section{qRT-PCR of HCV RNA}

The AgPath-ID ${ }^{\mathrm{TM}}$ One -Step RT-PCR kit was obtained from Applied Biosystems (Foster City, CA, USA). HCV PCR was performed with lower limit of detection $15 \mathrm{IU} / \mathrm{mL}$.

\section{Statistical analysis}

Data were coded and entered using the statistical package SPSS version 22. The odds ratio (OR) and 95\%CI were calculated to estimate the strength of associations between each genotype and alleles and patients and controls. $P$ values were considered significant when $P<0.05$.

\section{Results}

Patient characteristics are shown in Table 1.

Table 1. Baseline characteristics of patients

\begin{tabular}{|lccc|}
\hline \multicolumn{1}{c}{ Variable } & NR & RS & P \\
\hline Sex Females (\%) & $28(56)$ & $12(24)$ & 0.001 \\
Age, y & $42.9 \pm 9.5$ & $40.1 \pm 11.5$ & 0.188 \\
AST, IU/L & $57.7 \pm 35.9$ & $44.6 \pm 13.6$ & 0.018 \\
\hline ALT, IU/L & $61.5 \pm 31.2$ & $52.6 \pm 10.1$ & 0.060 \\
Alk. Phosphatase, IU/L & $113.0 \pm 60.2$ & $67.2 \pm 26.6$ & $<0.01$ \\
Bilirubin, g/dL & $0.8 \pm 0.3$ & $0.7 \pm 0.2$ & 0.139 \\
Albumin, g/dL & $4.2 \pm 0.7$ & $4.1 \pm 0.5$ & 0.137 \\
Creatinine, mg/dL & $0.9 \pm 0.2$ & $0.9 \pm 0.3$ & 0.720 \\
INR & $1.1 \pm 0.1$ & $1.1 \pm 0.1$ & 0.702 \\
WBC count/mL & $5.9 \pm 1.5$ & $6.6 \pm 2.0$ & 0.044 \\
\hline Platelets /mL & $223.6 \pm 67.4$ & $273.0 \pm 94.7$ & 0.003 \\
\hline & $11.0 \pm 23.4$ & $3.0 \pm 2.0$ & 0.020 \\
& F1: 14 & F1: 14 & 0.819 \\
\hline & F2: 29 & F2: 31 & \\
\hline HCV RNA, IU/mL x10 33 F & $1288 \pm 2288$ & $464 \pm 416$ & 0.015 \\
\hline Vitamin D level, ng/mL & $7.26 \pm 3.93$ & $5.31 \pm 2.83$ & 0.005 \\
\hline
\end{tabular}

All HCV-4 patients suffered vitamin D deficiency or insufficiency $(<30 \mathrm{ng} / \mathrm{mL})$ prior to treatment. Although all patients were either deficient or insufficient in vitamin D at baseline, responders had a significantly lower baseline vitamin D level than non-responders $(5.31 \pm 2.83 \mathrm{ng} / \mathrm{mL}$ vs. $7.26 \pm 3.93$ $\mathrm{ng} / \mathrm{mL}, P=0.005)$. There was a trend for higher baseline 
vitamin D level in higher fibrosis stages (F1: $5.5 \pm 2.6 \mathrm{ng} / \mathrm{mL}$, F2: $6.2 \pm 3.7 \mathrm{ng} / \mathrm{ml}, \mathrm{F} 3: 8.2 \pm 4.2 \mathrm{ng} / \mathrm{mL}$; F1 vs. F3: $P=0.03, \mathrm{~F} 1$ vs. F2: $\mathrm{P}=0.08$, F1 vs. $>\mathrm{F} 1: P=0.19$ ).

At the end of treatment, serum vitamin $\mathrm{D}$ levels remained unchanged in non-responders $(7.2 \pm 2.9 \mathrm{ng} / \mathrm{mL}$ vs $6.5 \pm 4.8 \mathrm{ng} / \mathrm{mL}$ at baseline and end of treatment respectively, $P=0.3$ ), while in responders serum vitamin D levels improved significantly $(5.3 \pm 2.8 \mathrm{ng} / \mathrm{mL}$ vs $65.8 \pm 16.2 \mathrm{ng} / \mathrm{mL}$ at baseline and end of treatment respectively, $P<0.001)$, Figure 1 . According to standard cut-off values, all 50 responders reached normal vitamin D levels ( $>30 \mathrm{ng} / \mathrm{mL})$ at the end of treatment while among non-responders only $1(2 \%)$ patient improved from being deficient to insufficient and none reached normal levels $(P<0.01$, Table 2$)$.

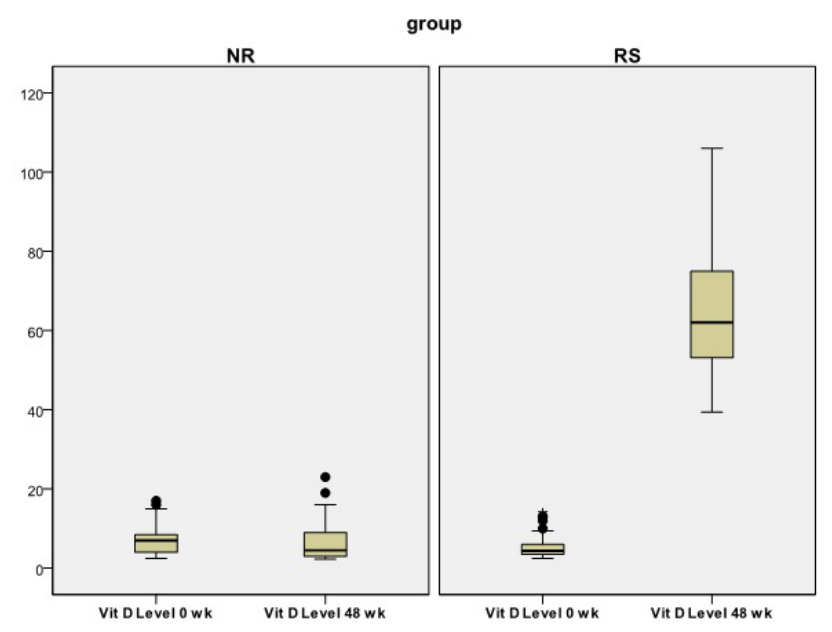

Fig. 1. Vitamin D level in different studied groups

Table 2. Vitamin D status before and after treatment

\begin{tabular}{|lc|c|c|}
\hline Vitamin D status & NR & RS & P value \\
\hline Before treatment & & & 0.25 \\
Deficient & 41 & 45 & \\
Insufficient & 9 & 5 & \\
Normal & 0 & 0 & \\
\hline After treatment & & & $<0.001$ \\
Deficient & 40 & 0 & \\
Insufficient & 10 & 0 & \\
Normal & 0 & 50 & \\
\hline
\end{tabular}

\section{VDRP}

Of the 100 studied patients, 35 had the FF FokI variant, 44 had the polymorphic ff variant, and 21 were heterozygous Ff. Of the non-responders, 45(90\%) patients had VDR FokI polymorphism, whether homo- or heterozygous (ff or Ff), in comparison to only $20(40 \%)$ patients in responders $(P<0.001$, Table 3). When analysing separate allelic combinations, $32(64 \%)$ patients with ff genotype were found in nonresponders vs. only $12(24 \%)$ in responders $(P<0.001)$, nonresponders included $13(26 \%)$ patients with $\mathrm{Ff}$ genotype vs $8(16 \%)$ in responders $(P=0.22)$. The FF variant was much more prevalent in responders than in non-responders: $30(60 \%)$ vs. 5(10\%) $(P<0.001)$, Figure 2 .

Table 3. VDR genotype in responders and non-responders

\begin{tabular}{|ll|l|l|}
\hline Genotype & \multicolumn{1}{c}{ NR } & \multicolumn{1}{c}{ RS } & P value \\
\hline ff & $32(64 \%)$ & $12(24 \%)$ & $<0.001$ \\
Ff & $13(26 \%)$ & $8(16 \%)$ & 0.22 \\
FF & $5(10 \%)$ & $30(60 \%)$ & $<0.001$ \\
(ff + Ff) & $45(90 \%)$ & $20(40 \%)$ & $<0.001$ \\
\hline
\end{tabular}

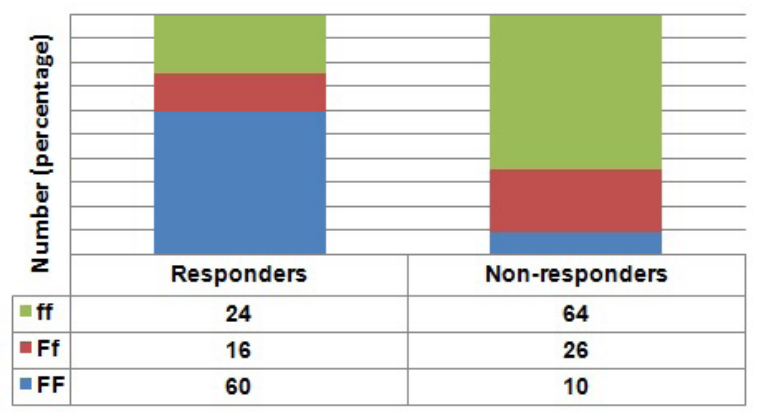

Fig. 2. Proportion of different VDR FokI genotypes in RS and NR. Numbers indicate \% of patients; $P<0.001$

Correlation of VDRP with baseline patient characteristics and laboratory data revealed that polymorphism was associated with higher ALT (ff: $63.2 \pm 30.8 \mathrm{U} / \mathrm{L}$, Ff: $48.5 \pm 19.5$ $\mathrm{U} / \mathrm{L}, \mathrm{FF}: 54.4 \pm 10.8 \mathrm{U} / \mathrm{L} ; P=0.04)$ and alkaline phosphatase (ff: $102.6 \pm 53.2 \mathrm{U} / \mathrm{L}$, Ff: $100.3 \pm 66.4 \mathrm{U} / \mathrm{L}, \mathrm{FF}: 68.3 \pm 29.4 \mathrm{U} / \mathrm{L}$; $P=0.007$ ) levels. VDRP showed no significant association with fibrosis levels and baseline vitamin D levels; however, there was a trend toward higher vitamin D levels in patients with homozygous polymorphism (ff) versus patients with the wild FF genotype $(7.0 \pm 3.7 \mathrm{ng} / \mathrm{mL}$ vs. $5.6 \pm 3.2 \mathrm{ng} / \mathrm{ml}, P=0.08)$.

PCR products restricted with FokI were shown in Figure 3 and 4 . The bands were shown after treatment with FokI as FF homozygous (266 bp), Ff heterozygous (266 bp and 193 bp) and ff homozygous (193 bp and $73 \mathrm{bp}$ ) according to restriction patterns.

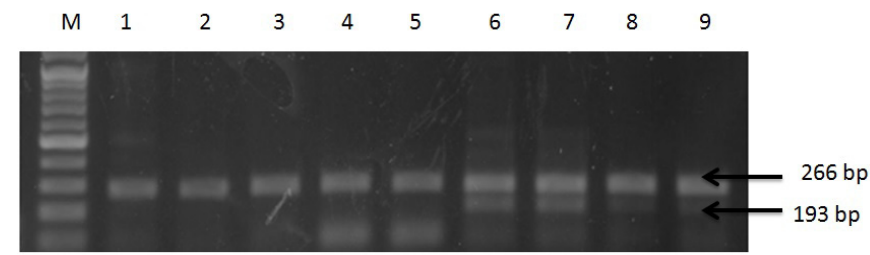

Fig. 3. Agarose gel electrophoresis showed FokI restriction patterns of the various genotypes of VDR.

Lane M: DNA ladder $(100,200, \ldots \ldots . . b p)$

Lane 1-3: 266 bp $P C R$ products before treatment of enzyme (FF genotype) Lane 4 and 5: $266 \mathrm{bp} P C R$ products after treatment of enzyme (FF genotype). Lane 6-9: 266, 193 and 73 bp $P C R$ products after treatment of enzyme (Ff genotype). 


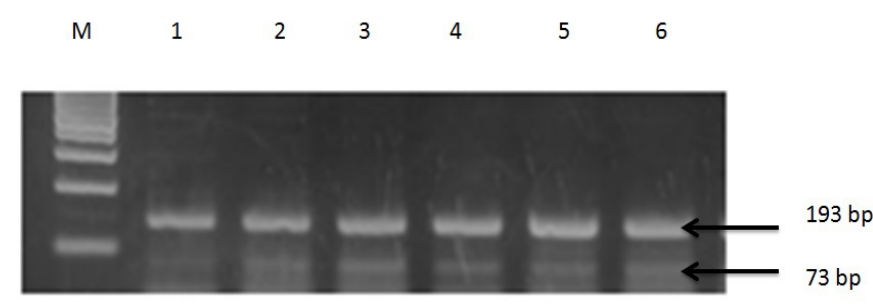

Fig. 4. Agarose gel electrophoresis showed FokI restriction pattern of ff genotype of VDR.

Lane M: DNA ladder $(100,200, \ldots . . . b p)$

Lane 1-6: 193 and 73 bp PCR products after treatment of enzyme (ff genotype).

\section{Predictors of response}

Multivariate analysis revealed that the following factors were associated with response (Table 4): lower age, alfafetoprotein, baseline vitamin D level, and absence of VDRP.

\section{Table 4.}

VDR polymorphism multivariate analysis with other predictors of antiviral response in $\mathrm{HCV}$ patients

\begin{tabular}{|l|c|c|c|}
\hline \multicolumn{1}{|c}{ Variable } & OR & $95 \%$ CI & P value \\
\hline Age & 1.1 & $1.0-1.3$ & 0.008 \\
Female gender & 16.0 & $2.6-100$ & 0.003 \\
AFP & 1.6 & $1.1-2.4$ & 0.02 \\
Baseline Vitamin D & 1.4 & $1.0-2.0$ & 0.02 \\
VDR polymorphism & 14.2 & $2.0-100$ & 0.008 \\
\hline
\end{tabular}

\section{Discussion}

The principle findings of our study are: a) the FokIVDRP is independently associated with poor response to therapy in HCV-4; b) chronic HCV-4 patients have a high prevalence of severe vitamin D deficiency; c) responders to treatment of HCV-4 have a remarkable improvement in serum vitamin $\mathrm{D}$ levels while non-responders do not; d) baseline vitamin D level does not correlate with a better response to treatment.

Immune-regulatory actions of vitamin $\mathrm{D}$ are thought to be exerted through the nuclear VDR, expressed in antigenpresenting cells and activated T cells. ${ }^{[13,14]}$ VDR determines interference and/or direct interaction with vitamin D responsive elements in the promoter regions of cytokine genes. Immune-regulatory effects of vitamin D occur through many mechanisms, including the down-regulated expression of MHC class II, co-stimulatory molecules, and IL-12..$^{[21,22]}$ On the other hand, vitamin D enhances IL-10 production and promotes dendritic cell apoptosis. ${ }^{[21,22]} \mathrm{A}$ few studies have recently explored the impact of genetic polymorphisms affecting the vitamin D pathway on the course of chronic HCV and its response to treatment. ${ }^{[8,16,17,23]}$ The CYP27B1-1260 promoter polymorphism (responsible for production of 1,25-dihydroxyvitamin D) has been shown to be a predictor of poor response to treatment in genotypes 1,2 and $3,{ }^{[8]}$ especially in difficult- to-treat patients. ${ }^{[16,23]}$ These results have been negated, however, by 2 recent large studies that revealed no association between CYP27B1-1260 polymorphism and response to treatment in predominantly genotype 1 cohorts of patients. ${ }^{[17,24]}$ Baur et al. reported that the bAt(CCA) haplotype was associated with impaired response to $\mathrm{HCV}$ treatment, a finding that was confirmed by Garcia-Martin et al. ${ }^{[17,24]} \mathrm{A}$ single nucleotide polymorphism of the VDR gene (rs2228570 T/C) also had a negative impact on treatment response. ${ }^{[17]}$ The VDR FokI polymorphism restriction site is located on exon 2 in the $5^{\prime}$ coding region of the gene. ${ }^{[25]}$ The FokI polymorphism has been correlated with many immunologic processes including cancers such as breast, prostate and colorectal cancer, autoimmune hepatitis and TB. ${ }^{[6,23-25]}$ To our knowledge only one study has assessed the role of VDRP in HCV, in a mixed population including genotypes 1,2 and 3, VDRP showed no significant association with treatment response. ${ }^{[8]}$ Our study is the first to assess the effect of VDRP in HCV-4. Our results show a significant and independent negative impact of VDRP on treatment response where $90 \%$ of non-responders were carriers of the restriction allele (f) in comparison to only $40 \%$ of responders $(P<0.001)$. This significance was maintained in multivariate analysis $(P=0.008)$. The impact of FokI polymorphism on response to treatment is plausible in view of the profound effects it has on the intracellular pathway of vitamin D signalling. VDR whose function is impaired by FokI polymorphism determines interference and/ or direct interaction with vitamin $\mathrm{D}$ responsive elements in the promoter regions of cytokine genes. ${ }^{[26]}$

Our results also show an association between VDR FokI polymorphism and higher ALT and alkaline phosphatase levels. It might therefore be plausible that vitamin D deficiency or a VDR polymorphism impairing the vitamin D cellular pathway could lead to a proinflammatory milieu and promote hepatic inflammation, which is reflected in elevated ALT levels. This notion is supported by recent studies correlating low serum vitamin D levels with higher inflammatory activity indices in liver biopsies of HCV-infected patients. ${ }^{[7]}$ Even patients with unexplained elevations of ALT have been shown to have lower serum vitamin D levels. ${ }^{[27]}$ The correlation of VDR FokI polymorphism with higher alkaline phosphatase levels may also be partly explained by the concept of impairing the anti-inflammatory effects of vitamin D, as over $90 \%$ of HCVinfected patients have evidence of bile duct inflammation

Another possible explanation could be the deleterious effect of the VDR polymorphism on bone metabolism, thus increasing bone-specific alkaline phosphatase, although the results of studies testing the association of FokI polymorphism with osteoporosis or altered bone turnover have been discordant. ${ }^{[28,29]}$

All our HCV-4 patients had suboptimal vitamin D levels with the majority being severely deficient $(86 \%)$. Possible explanations for the association of $\mathrm{HCV}$ with vitamin D deficiency have included decreased 25-alpha hydroxylation in the liver, HCV may have the ability to directly suppress 25-alpha hydroxylation through inducing cytokines and 
oxidative stresses, and a recent study has shown that $\mathrm{HCV}$ alters lipid metabolism directly reducing production of 7-dehydrocholesterol, the precursor of endogenouslyproduced vitamin D. ${ }^{[30,31]}$ The independent effect of $\mathrm{HCV}$ on vitamin $\mathrm{D}$ levels is strongly supported by our finding of the remarkable improvement in vitamin D levels after successful eradication of $\mathrm{HCV}$ and its persistence in non-responders. Further studies are definitely recommended to depict the exact mechanisms by which $\mathrm{HCV}$ alters vitamin D production and metabolism.

Perhaps an unexpected finding in our study was that vitamin D deficiency did not correlate with poor response to treatment. This comes in contrast to many studies that have shown that a lower vitamin $\mathrm{D}$ level is associated with poor response to interferon-based treatment in genotypes 1,2 and $3{ }^{[7-9]}$ Our study is not, however, the only one to negate such evidence; a recent large study including 274 genotype 1 patients not only demonstrated a lack of association between vitamin $\mathrm{D}$ levels and response to treatment, but responders actually had lower baseline vitamin D levels than nonresponders in univariate analysis $(76.6 \mathrm{nmol} / \mathrm{L}$ vs. $84.7 \mathrm{nmol} / \mathrm{L}$, respectively; $P=0.03){ }^{\left[{ }^{10]}\right.}$ Another large study including 310 genotype 1 patients also found no association. ${ }^{[24]}$ In 2 studies that frankly showed no association of response with vitamin D level [our current study and Kitson et al.,2013] vitamin D levels were measured by LC-MS/MS methodology, ${ }^{[10,32]}$ avoiding fallacies that may be induced by other commercially available kits. Another noticeable difference between the studies is the prevalence of advanced fibrosis. In the 3 studies that reported no association of vitamin D with response [our current study, Kitson et al.,2013, and Grammatikos et al.,2011] prevalence of advanced fibrosis was $12 \%, 14 \%$ and $19 \%$, while Bitetto et al. ${ }^{[9]}$ and Petta at al. ${ }^{[7]}$, who both found a relation between vitamin D levels and response, had patients with a high prevalence of advanced fibrosis $(29 \%$ and $28 \%)^{[7,9,10,24]}$ This observation leads us to wonder whether the association of lower vitamin $\mathrm{D}$ with a poor response is not strongly confounded by the advanced fibrosis, even though strictly statistically speaking the multivariate analyses in these studies should have excluded this possibility.

Our study has some limitations. First is the retrospective nature of the study. Second, we had no standardization of the time (season) when samples were taken, which could influence vitamin D levels. Third, our cohort consisted of only Egyptian patients and thus results could not be extrapolated to other populations, especially because ethnic differences have been shown in the allelic frequencies in VDR polymorphisms. ${ }^{[33]}$ Fourth, our study design also put some limitation on our interpretation of results; we started by selecting a fixed number of responders and non-responders (limited by samples availability) and compared them, rather than starting with a single cohort of patients and comparing all responders and non-responders. Strictly statistically speaking this approach did not allow us to express the SVR rate in each genetic variant, but rather the prevalence of each genetic variant in both responders and non-responders. Nevertheless, with the obvious high prevalence of the $f$ allele in nonresponders, it could be reasonably and confidently deduced that the f allele is strongly associated with a lower SVR. Fifth, our study did not assess IL28 gene polymorphisms, which have a strong impact on response.

In conclusion, the VDR FokI gene polymorphism is associated with poor response to treatment in HCV-4 patients. Our study reveals significant vitamin D deficiency in HCV4 patients that reverts with eradication of $\mathrm{HCV}$, yet there is no association of vitamin D levels with response. A larger study assessing the FokI polymorphism, IL28 polymorphism, and vitamin D levels and possibly the effect of vitamin D supplementation is warranted.

\section{Competing interests}

The authors declare that they have no conflict of interest.

\section{References}

1. Egyptian Ministry of Health. Annual report: 2007. Available from: http://www.mohp.gov.eg/Main.asp

2. Kamal SM, Nasser IA. Hepatitis C genotype 4: what we know and what we don't yet know. Hepatology. 2008; 47:1371-83.

3. Lawitz E, Mangia A, Wyles D, Rodriguez-Torres M, Hassanein T, Gordon SC, et al. Sofosbuvir for previously untreated chronic hepatitis $\mathrm{C}$ infection. N Engl J Med. 2013;368(20):1878-87

4. Lawitz E, Lalezari JP, Hassanein T, Kowdley KV, Poordad FF, Sheikh AM, et al. Sofosbuvir in combination with peginterferon alfa-2a and ribavirin for non-cirrhotic, treatment-naive patients with genotypes 1,2 , and 3 hepatitis $\mathrm{C}$ infection: a randomised, double-blind, phase 2 trial. Lancet Infect Dis. 2013;13(5):401-8.

5. Pol S, Ghalib RH, Rustgi VK, Martorell C, Everson GT, Tatum HA, et al. Daclatasvir for previously untreated chronic hepatitis C genotype-1 infection: a randomised, parallelgroup, double-blind, placebo-controlled, dose-finding, phase 2a trial. Lancet Infect Dis. 2012;12(9):671-7.

6. Kitson MT, Roberts SK. D-livering the message: the importance of vitamin D status in chronic liver disease $\mathrm{J}$ Hepatol. 2012;57(4):897-909

7. Petta $\mathrm{S}$, Cammà $\mathrm{C}$, Scazzone $\mathrm{C}$, Tripodo $\mathrm{C}$, Di Marco $\mathrm{V}$, Bono A, et al. Low vitamin D serum level is related to severe fibrosis and low responsiveness to interferon-based therapy in genotype 1 chronic hepatitis C. Hepatology. 2010;51(4):1158-67.

8. Lange CM, Bojunga J, Ramos-Lopez E, von Wagner M, Hassler A, Vermehren J, et al. Vitamin D deficiency and a CYP27B1-1260 promoter polymorphism are associated with chronic hepatitis $\mathrm{C}$ and poor response to interferon-alfa based therapy. J Hepatol. 2011;54(5):887-93.

9. Bitetto D, Fattovich G, Fabris C, Ceriani E, Falleti E, Fornasiere E, et al. Complementary role of vitamin $\mathrm{D}$ deficiency and the interleukin-28B rs12979860 C/T polymorphism in predicting antiviral response in chronic hepatitis C. Hepatology. 2011;53(4):1118-26.

10. Kitson MT, Dore GJ, George J, Button P, McCaughan GW, Crawford DH,et al. Vitamin D status does not predict sustained virologic response or fibrosis stage in chronic hepatitis $\mathrm{C}$ genotype 1 infection. J Hepatol. 2013;58(3):467-72.

11. Abu-Mouch S, Fireman Z, Jarchovsky J, Zeina AR, Assy 
N. Vitamin D supplementation improves sustained virologic response in chronic hepatitis $\mathrm{C}$ (genotype 1)-naïve patients. World J Gastroenterol. 2011;17(47):5184-90.

12. Nimer A, Mouch A. Vitamin D improves viral response in hepatitis C genotype 2-3 naïve patients. World J Gastroenterol. 2012;18:800-5.

13. Zuniga S, Firrincieli D, Housset C, Chignard N. Vitamin $\mathrm{D}$ and the vitamin $\mathrm{D}$ receptor in liver pathophysiology. Clin Res Hepatol Gastroenterol. 2011; 35(4):295-302.

14. Mora JR, Iwata M, von Andrian UH. Vitamin effects on the immune system: vitamins A and D take centre stage. Nat Rev Immunol. 2008; 8(9):685-98.

15. Falleti E, Bitetto D, Fabris C, Cmet S, Fornasiere E, Cussigh A, et al. Association between vitamin D receptor genetic polymorphisms and acute cellular rejection in livertransplanted patients. Transpl Int. 2012;25(3):314-22

16. Lange CM, Bibert S, Kutalik Z, Burgisser P, Cerny A, Dufour JF, et al. A Genetic Validation Study Reveals a Role of Vitamin D Metabolism in the Response to Interferon-Alfa-Based Therapy of Chronic Hepatitis C. PLoS One. 2012;7(7):e40159

17. García-Martín E, Agúndez JA, Maestro ML, Suárez A, Vidaurreta M, Martínez C, et al. Influence of Vitamin D-Related Gene Polymorphisms (CYP27B and VDR) on the Response to Interferon/Ribavirin Therapy in Chronic Hepatitis C. PLoS One. 2013;8(9):e74764

18. Fan L, Tu X, Zhu Y, Zhou L, Pfeiffer T, Feltens R, et al. Genetic association of vitamin $\mathrm{D}$ receptor polymorphisms with autoimmune hepatitis and primary biliary cirrhosis in the Chinese. J Gastroenterol Hepatol. 2005;20(2):249-55.

19. Wilkinson RJ, Llewelyn M, Toossi Z, Patel P, Pasvol $\mathrm{G}$, Lalvani A, et al. Influence of vitamin D deficiency and vitamin D receptor polymorphisms on tuberculosis among Gujarati Asians in west London: a case-control study. Lancet. 2000;355(9204):618-21.

20. Köstner K, Denzer N, Müller CS, Klein R, Tilgen $\mathrm{W}$, Reichrath J. The relevance of vitamin D receptor (VDR) gene polymorphisms for cancer: a review of the literature. Anticancer Res. 2009;29(9):3511-36.

21. van Etten E, Mathieu C. Immunoregulation by 1,25-dihydroxyvitamin D3: basic concepts. J Steroid Biochem Mol Biol. 2005; 97(1-2):93-101.

22. Adams JS, Liu PT, Chun R, Modlin RL, Hewison M. Vitamin D in defense of the human immune response. Ann N Y Acad Sci. 2007; 1117: 94-105.

23. Thanapirom K, Suksawatamnuay S, Tangkijvanich P,
Treeprasertsuk S, Poovorawan Y, Akkarathamrongsin S, Komolmit P. The Promoter Polymorphism of Cyp27b1 Gene Predicts Poor Response to Interferon-Alfa Based Therapy in Difficult-to-Treat Chronic Hepatitis C Genotype in Asian Population. Gastroenterology. 2013;144(5 Suppl1):S-952

24. Grammatikos G, Susser S, Schwendy S, et al. Neither vitamin D levels nor genetic polymorphisms within the 25 -, and the 1a-vitamin D-hydroxylase are associated with viral clearance following interferon-based therapy in patients with genotype 1 chronic hepatitis C. Hepatology. 2011;54:987A. 25. Baur K, Mertens JC, Schmitt J, Iwata R, Stieger B, Frei $\mathrm{P}$, et al. The vitamin $\mathrm{D}$ receptor gene bAt (CCA) haplotype impairs the response to pegylated-interferon/ribavirinbased therapy in chronic hepatitis $\mathrm{C}$ patients. Antivir Ther. 2012;17(3):541-7

26. Alimirah F, Peng X, Murillo G, Mehta RG. Functional Significance of Vitamin D Receptor FokI Polymorphism in Human Breast Cancer Cells. PLoS One. 2011;6(1):e16024 27. Liangpunsakul S, Chalasani N. Serum vitamin D concentrations and unexplained elevation in ALT among US adults. Dig Dis Sci. 2011;56(7):2124-9.

28. Chen HY, Chen WC, Hsu CD, Tsai FJ, Tsai $\mathrm{CH}$. Relation of vitamin D receptor FokI start codon polymorphism to bone mineral density and occurrence of osteoporosis in postmenopausal women in Taiwan. Acta Obstet Gynecol Scand. 2002;81(2):93-8.

29. Zintzaras E, Rodopoulou P, Koukoulis GN. BsmI, TaqI, ApaI and FokI polymorphisms in the vitamin D receptor (VDR) gene and the risk of osteoporosis: a meta-analysis. Dis Markers. 2006;22(6-8):317-26.

30. Clark PJ, Thompson AJ, Vock DM, Kratz LE, Tolun AA, Muir AJ, et al. Hepatitis $\mathrm{C}$ virus selectively perturbs the distal cholesterol synthesis pathway in a genotype-specific manner. Hepatology. 2012;56(1):49-56.

31. Bellecave P, Sarasin-Filipowicz M, Donzé O, Kennel A, Gouttenoire J, Meylan E, et al. Cleavage of mitochondrial antiviral signaling protein in the liver of patients with chronic hepatitis $\mathrm{C}$ correlates with a reduced activation of the endogenous interferon system. Hepatology. 2010;51(4):1127-36.

32. Vogeser M, Kyriatsoulis A, Huber E, Kobold U. Candidate reference method or the quantification of circulating 25-hyxroxyvitamin D3 by liquid chromatography-tandem mass spectrometry. Clin Chem. 2004;50(8):1415-7.

33. Uitterlinden AG, Fang Y, Van MeursJB, Pols HA, Van Leeuwen JP. Genetics and biology of vitamin D receptor polymorphisms. Gene. 2004;338(2):143-56. 